University of Nebraska - Lincoln

DigitalCommons@University of Nebraska - Lincoln

\title{
Photofragmentation of closo-Carboranes Part 1: Energetics of Decomposition
}

\author{
Danqin Feng \\ University of Nebraska-Lincoln \\ Jing Liu \\ University of Nebraska-Lincoln \\ Adam P. Hitchcock
}

A. L. David Kilcoyne

Tolek Tyliszczak

See next page for additional authors

Follow this and additional works at: https://digitalcommons.unl.edu/physicsdowben

Part of the Physics Commons

Feng, Danqin; Liu, Jing; Hitchcock, Adam P.; Kilcoyne, A. L. David; Tyliszczak, Tolek; Riehs, Norman F.; Rühl, Eckart; Bozek, John D.; Mcllroy, David; and Dowben, Peter A., "Photofragmentation of closo-Carboranes Part 1: Energetics of Decomposition" (2008). Peter Dowben Publications. 229.

https://digitalcommons.unl.edu/physicsdowben/229

This Article is brought to you for free and open access by the Research Papers in Physics and Astronomy at DigitalCommons@University of Nebraska - Lincoln. It has been accepted for inclusion in Peter Dowben Publications by an authorized administrator of DigitalCommons@University of Nebraska - Lincoln. 


\section{Authors}

Danqin Feng, Jing Liu, Adam P. Hitchcock, A. L. David Kilcoyne, Tolek Tyliszczak, Norman F. Riehs, Eckart Rühl, John D. Bozek, David Mcllroy, and Peter A. Dowben 


\title{
Photofragmentation of closo-Carboranes Part 1: Energetics of Decomposition
}

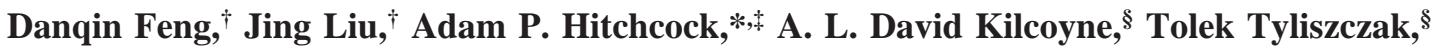 \\ Norman F. Riehs, ${ }^{\|}$Eckart Riihl, ${ }^{*, \|}$ John D. Bozek, ${ }^{\perp}$ David McIlroy, $\$$ and Peter A. Dowben*, $\dagger$ \\ Department of Physics and Astronomy and the Nebraska Center for Materials and Nanoscience, University of \\ Nebraska-Lincoln, Lincoln, Nebraska 68588-0111, Department of Chemistry, McMaster University, Hamilton, \\ Ontario, Canada, L8S 4M1, Advanced Light Source, Lawrence-Berkeley Laboratory, One Cyclotron Road, \\ Berkeley, California 94720-8225, Physikalische und Theoretische Chemie, Institut für Chemie und Biochemie, \\ Freie Universität Berlin, Takustr. 3, 14195 Berlin, Germany, Stanford Linear Accelerator Center, 2575 Sand \\ Hill Road, Mail Stop 18, Menlo Park, California 94025-7015, and Department of Physics, Engineering and \\ Physics Building, University of Idaho, Moscow, Idaho 83844-0903
}

Received: November 19, 2007; In Final Form: January 11, 2008

\begin{abstract}
The ionic fragmentation following $\mathrm{B} 1 \mathrm{~s}$ and $\mathrm{C} 1 \mathrm{~s}$ excitation of three isomeric carborane cage compounds [closo-dicarbadodecaboranes: orthocarborane $\left(1,2-\mathrm{C}_{2} \mathrm{~B}_{10} \mathrm{H}_{12}\right)$, metacarborane $\left(1,7-\mathrm{C}_{2} \mathrm{~B}_{10} \mathrm{H}_{12}\right)$, and paracarborane $\left.\left(1,12-\mathrm{C}_{2} \mathrm{~B}_{10} \mathrm{H}_{12}\right)\right]$ is compared with the energetics of decomposition. The fragmentation yields for all three molecules are quite similar. Thermodynamic cycles are constructed for neutral and ionic species in an attempt to systemically characterize single-ion closo-carborane creation and fragmentation processes. Lower energy decomposition processes are favored. Among the ionic species, the photon-induced decomposition is dominated by $\mathrm{BH}^{+}$and $\mathrm{BH}_{2}{ }^{+}$fragment loss. Changes in ion yield associated with core to bound excitations are observed.
\end{abstract}

\section{Introduction}

The ability to generate semiconducting grades of boron carbide by plasma-enhanced chemical vapor-phase decomposition and deposition (PECVD) of carboranes permits the development of corrosion resistant, high-temperature boron carbide semiconductor devices with many applications including neutron detection. ${ }^{1-7}$ It is now clear that these boron carbides, of approximate stoichiometry " $\mathrm{C}_{2} \mathrm{~B}_{10} \mathrm{H}_{x}$ " (where $x$ represents up to $\sim 5 \%$ molar fraction of hydrogen), exhibit a range of electronic properties (e.g., p-type or n-type ${ }^{1,8}$ and differing band gaps $^{9}$ ) presumably as a result of differing electronic structures originating in differences in polytype (molecular structure). ${ }^{1,8,9}$ It has been observed that the majority carrier in one " $\mathrm{C}_{2} \mathrm{~B}_{10} \mathrm{H}_{x}$ " boron carbide semiconductor relative to another and the concomitant placement of the Fermi level within the semiconducting gap appears to "mirror" the relative placement of the free molecule chemical potential relative to the Fermi level for molecular films ${ }^{10}$ of the corresponding source compound (i.e., the pertinent closo-carborane decomposed to form the semiconductor). $1,8,10,11$

If the adsorbate dipole moment indeed influences the molecular orbital alignment for the adsorbed molecular films, we suggest that decomposition of the closo-carboranes to form the " $\mathrm{C}_{2} \mathrm{~B}_{10} \mathrm{H}_{x}$ " boron carbide semiconductor does not result in complete fragmentation of the icosahedral cage, as might be suggested by cluster calculations, ${ }^{12}$ and the resulting carrier concentration is influenced, at least somewhat, by space charge layers. Thus, from the observed materials properties, one might

* To whom correspondence should be addressed. Phone: 402-472-9838. Fax: (402) 472-2879. E-mail: pdowben@unl.edu.

† University of Nebraska-Lincoln.

$\div$ McMaster University.

$\S$ Lawrence-Berkeley Laboratory.

"Freie Universität Berlin.

$\perp$ Stanford Linear Accelerator Center.

$\$$ University of Idaho. infer that complete dissociation of the molecular icosahedra does not occur in the plasma decomposition of the closo-carboranes. Regrettably, relatively little is known about the detailed decomposition mechanisms of the closo-carboranes. ${ }^{12}$

The B 1s and C 1s oscillator strength spectra of closocarboranes provide only the starting point and necessary spectroscopic background for understanding the changes of the fragmentation yields with photon energy. In prior studies of the closo-carboranes, the $\mathrm{B} 1 \mathrm{~s}$ and $\mathrm{C} 1 \mathrm{~s}$ excitation spectra of orthocarborane, metacarborane, and paracarborane were recorded with both dipole regime electron impact and synchrotron radiation. ${ }^{13}$ This work explores the photoion fragmentation processes of the closo-carboranes. Multiple ion creation and molecular fission are certainly possible and highly likely at energies above the core thresholds and will be more directly addressed in subsequent paper(s).

The modeling of molecular decomposition processes in chemical vapor deposition (CVD) is particularly valuable in developing a clear picture of CVD. Density functional theory and semiempirical methods have both been used to calculate the energetics of closo-carborane decomposition. Thermodynamic cycles have been used to elucidate the mechanisms of part of the electron- and photon- induced decomposition pathways for the three different isomers of closo-dicarbadodecaboranes: orthocarborane $\left(1,2-\mathrm{C}_{2} \mathrm{~B}_{10} \mathrm{H}_{12}\right)$, metacarborane $(1,7-$ $\left.\mathrm{C}_{2} \mathrm{~B}_{10} \mathrm{H}_{12}\right)$, and paracarborane $\left(1,12-\mathrm{C}_{2} \mathrm{~B}_{10} \mathrm{H}_{12}\right)$. All three isomers have icosahedral-like structures, differing only in the placement of the two carbons in the icosahedra, as shown in Figure 1.

\section{Experimental and Theoretical Details}

All isomers of $\mathrm{C}_{2} \mathrm{~B}_{10} \mathrm{H}_{12}$, i.e., orthocarborane (closo-1,2dicarbadodecaborane or 1,2- $\mathrm{C}_{2} \mathrm{~B}_{10} \mathrm{H}_{12}$ ), metacarborane (closo1,7-dicarbadodecaborane or 1,7- $\mathrm{C}_{2} \mathrm{~B}_{10} \mathrm{H}_{12}$ ), and paracarborane (closo-1,12-dicarbadodecaborane or 1,12- $\mathrm{C}_{2} \mathrm{~B}_{10} \mathrm{H}_{12}$ ), were purchased from either Katchem or Aldrich or prepared using the 


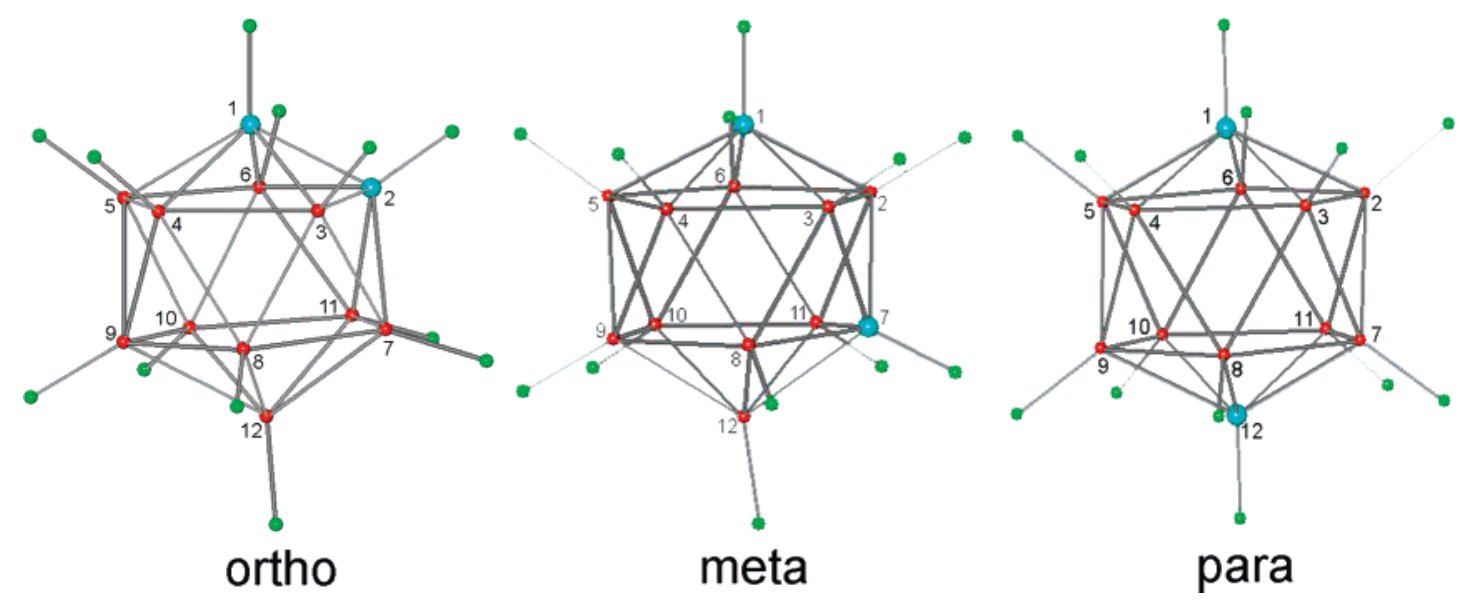

Figure 1. Structures of closo-1,2-orthocarborane, closo-1,7-metacarborane, and closo-1,12-paracarborane $\left(\mathrm{C}_{2} \mathrm{~B}_{10} \mathrm{H}_{12}\right)$ and their atom-numbering schemes.

procedures described in ref 13. All solvents (tetrahydrofuran, pentane, and diethyl ether) were reagent grade or better and distilled from the appropriate drying agents $(\mathrm{Na})$ under a dry nitrogen atmosphere prior to use. After drying, all organic solvents were degassed with a dry nitrogen stream and then by repeated freeze-thaw cycles, resublimed, with purity in all cases confirmed by NMR spectroscopy, and then stored in vacuo prior to use. Deuterated solvents were used as received and, after degassing, stored over $4 \AA$ molecular sieves prior to use. The commercially available anhydrous chemicals were either used as received or purified by the method indicated and, where possible, stored over $4 \AA$ molecular sieves prior to use. The identity and purity of all compounds were determined by nuclear magnetic resonance (NMR), infrared spectroscopy (IR), and mass spectral measurements and compared with literature values. NMR spectra were obtained on a Bruker AVANCE400 operating at ${ }^{1} \mathrm{H} 400.1 \mathrm{MHz},{ }^{13} \mathrm{C} 100.6 \mathrm{MHz}$, and ${ }^{11} \mathrm{~B} 128.38 \mathrm{MHz}$. Proton and carbon spectra were referenced to solvent and boron spectra to an insert of $\mathrm{BF}_{3} \cdot \mathrm{Et}_{2} \mathrm{O}$.

The photoexcitation spectra were recorded using both total electron yield and total ion yield detection at beam-line 9.0.1 of the Advanced Light Source, ${ }^{14}$ as described previously. ${ }^{13}$ The beam-line consisted of a spherical grating monochromator illuminated by the radiation from an undulator. Rather narrow entrance and exit slits were used, typically $\sim 10 \mu \mathrm{m}$. The photon resolution was better than $0.1 \mathrm{eV}$ fwhm.

In investigating the ionic fragmentation, a time-of-flight mass spectrometer was used. ${ }^{14 a}$ The time-of-flight mass spectrometer consisted of a two-stage acceleration region separated by grids followed by a $30 \mathrm{~cm}$ drift tube with a multichannel plate detector for ion detection. Wiley-McLaren focusing conditions were used. ${ }^{15} \mathrm{~A}-250 \mathrm{~V} / \mathrm{cm}$ extraction field was used for the ions. Under these conditions, splitting was not detected for any of the mass peaks, indicating there was negligible distortion of the yields due to loss of high kinetic energy ions, although isotopic and $\mathrm{Y}-\mathrm{H}_{x}$ distributions tend to blur any such effects, except for $\mathrm{H}^{+}$. The overall efficiency for ion detection is estimated to be about $15 \%$. The start of the flight time scale was the signal from an electron accelerated by a field of +250 $\mathrm{V} / \mathrm{cm}$ to a channeltron adjacent to the ionization region.

The ground-state energies for a variety of carborane clusters were calculated using a semiempirical method PM3 as well as with density function theory (DFT) using a standard 6-31 G* basis set and the Perdew-Wang 91 exchange correlation potential. ${ }^{16}$ Both the semiempirical and ab initio calculations were geometry optimized to obtain the lowest unrestricted
Hartree-Fock (UHF) energy states. The ground-state geometries of these carborane clusters were optimized using energy minimization with semiempirical method PM3 before the DFT calculations to save on computational time. The total energy is better estimated using DFT, although there are serious deficiencies in using ab initio DFT to model the electronic structure of the carboranes. ${ }^{10,16}$ Although correctly assessing the strength of the exchange and correlation interactions in formation of the highest occupied (HOMO) to the lowest unoccupied (LUMO) molecular orbitals gaps is a problem in DFT, this is one of the better approaches to estimating the chemical energetics.

\section{Ionic Fragmentation of the closo-Carboranes}

To identify selectivity in fragmentation processes, quantitative yields are required, and thus, it is important to understand the relationship between measured signals and the true partial photoionization cross-section. The photoionization cross-section for the boron and carbon sites can be seen from the photoionization total yield spectra of closo-carboranes, as shown in Figure 2 and previously described. ${ }^{13}$ From the comparison of the $\mathrm{B} 1 \mathrm{~s}$ and $\mathrm{C} 1 \mathrm{~s}$ oscillator strength spectra of closometacarborane, we can see the spectra of the three closocarboranes are relatively similar. The B 1 s spectra of all isomers are dominated by the strong resonance centered near $192 \mathrm{eV}$. At higher resolution, an isomer-dependent fine structure is visible within this band, indicating that the B 1s spectra are sensitive to differences in the electronic structure of the isomers. ${ }^{13}$ For orthocarborane (nominally $C_{2 v}$ symmetry), the $192 \mathrm{eV}$ band was assigned ${ }^{13,17}$ to overlap of excitations to the $10 \mathrm{a}^{\prime \prime}$ and $17 \mathrm{a}^{\prime}$ molecular orbitals from all the B 1s orbitals (in the point group $C_{S}$ symmetry). The other prominent B 1s spectral features are two broad bands located in the B 1s continuum (197 and $202 \mathrm{eV}$ ). In the para and meta isomers there is a distinct shoulder at $195 \mathrm{eV}$ that is not seen in orthocarborane. The higher energy continuum transitions in orthocarborane have been attributed to excitations to antibonding $\sigma^{*}$ orbitals of unspecified symmetry. ${ }^{13,17}$ A more sophisticated treatment of the electronic structure and spectroscopy has been undertaken elsewhere. ${ }^{13}$ Surprisingly, the B 1s spectrum for orthocarborane in Figure 2 is very much like the untreated (native) NEXAFS spectra of semiconducting boron carbide, ${ }^{18}$ suggesting that at the very least there are large icosahedral fragments in boron carbide.

The $\mathrm{C}$ 1s photoionization total yield spectra of the isomeric carboranes are also presented in Figure 2, again using the highresolution total ion yield (TIY). The energies, term values, and proposed assignments as with the B 1s spectra have been 


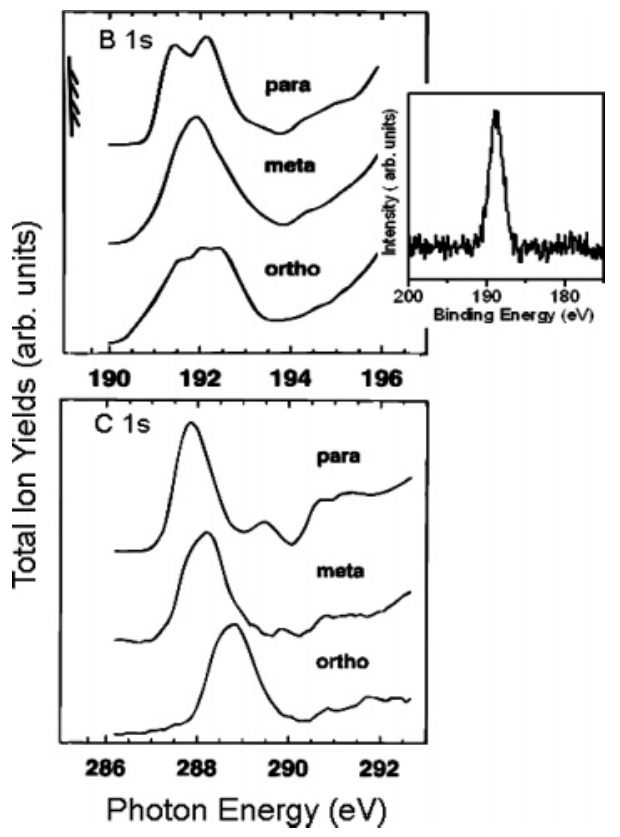

Figure 2. Total ion yield at the $\mathrm{B} 1 \mathrm{~s}$ and $\mathrm{C} 1 \mathrm{~s}$ cores for closodicarbadodecaboranes, orthocarborane $\left(1,2-\mathrm{C}_{2} \mathrm{~B}_{10} \mathrm{H}_{12}\right)$, metacarborane $\left(1,7-\mathrm{C}_{2} \mathrm{~B}_{10} \mathrm{H}_{12}\right)$, and paracarborane $\left(1,12-\mathrm{C}_{2} \mathrm{~B}_{10} \mathrm{H}_{12}\right)$, as a function of photon energy, with the $\mathrm{B} 1 \mathrm{~s}$ threshold of $188.9 \mathrm{eV}$, determined from XPS. (Inset) X-ray photoemission spectrum (XPS) of the B 1s core from condensed molecular films of orthocarborane. The Fermi level was established from the clean, well-ordered $\mathrm{Cu}(111)$ single crystal and $\mathrm{Au}(111)$ thin film substrates before deposition.

previously assigned. ${ }^{13,17}$ As with the B 1s spectra, there are subtle but significant and interpretable ${ }^{13}$ differences in the $\mathrm{C}$ 1s spectra of these isomers. The intense lowest energy feature in the 287.9-288.7 eV range occurs at different energies for each of the three isomers. In addition, the spectra also differ in shape above $290 \mathrm{eV}$ excitation energy. ${ }^{13}$ These differences between the isomers, however, appear to have little influence on the qualitatively similar fragmentation processes observed for all three isomers.

We measured the X-ray photoemission spectra of condensed carborane molecular films, as described elsewhere. ${ }^{10}$ The core level binding energies, with respect to the Fermi level of a reference metallic electrode, are a rough guide to the core-level thresholds of $188.9 \pm 0.2 \mathrm{eV}$ for the B $1 \mathrm{~s}$ threshold, as determined from the XPS in the inset to Figure 2.

Time-of-flight ion mass spectra of the three carborane isomers obtained with both electron impact and photon ionization are shown in Figure 3. As seen in Figure 3, the most dramatic difference between the electron impact and the photoionization mass spectra is in the parent ion yield. The fragmentation yields differ significantly from those following valence ionization using $70 \mathrm{eV}$ electron impact and $202 \mathrm{eV}$ incident photons but do not vary greatly in different B $1 \mathrm{~s}$ states. By contrast, the parent ion, with some contribution from fragment ions involving loss of one $\mathrm{H}$ atom, is by far the dominant signal in the electron impact mass spectrum. Indeed, the high stability of the parent ion produced by electron impact valence shell ionization has been noted in previous discussions of the mass spectra of the carboranes. ${ }^{19}$ At $70 \mathrm{eV}$ impact energy fully $74 \%$ of all ions observed have the mass of the parent ion, missing possibly only the mass of a hydrogen or two. ${ }^{20}$ In contrast, under our detection conditions the parent ion yield is only $\sim 3 \%$ below the onset of B 1s core excitation and drops to less than $1 \%$ above the B $1 \mathrm{~s}$ ionization potential (IP). The TOF signal is associated with $\mathrm{Y}_{x}^{+}$ ions (where $\mathrm{Y}=\mathrm{BH}$ or $\mathrm{CH}$ ), with all possible $x$ values, although

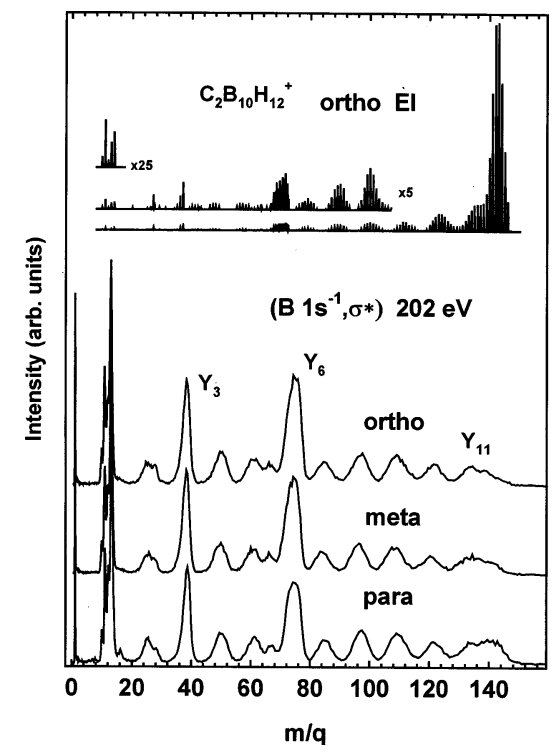

Figure 3. Time-of-flight (TOF) mass spectra of the isomeric carboranes taken at a photon energy of $202 \mathrm{eV}$ (B $1 \mathrm{~s} \rightarrow \sigma^{*}$ transition). The peaks correspond to cluster fragments with all possible numbers of vertices, denoted as $\mathrm{Y}_{n}^{+}$, where $\mathrm{Y}$ represents $\mathrm{BH}$ or $\mathrm{CH}$. The top spectrum is from electron impact using electron kinetic energies of $70 \mathrm{eV}$ (well below the core threshold).

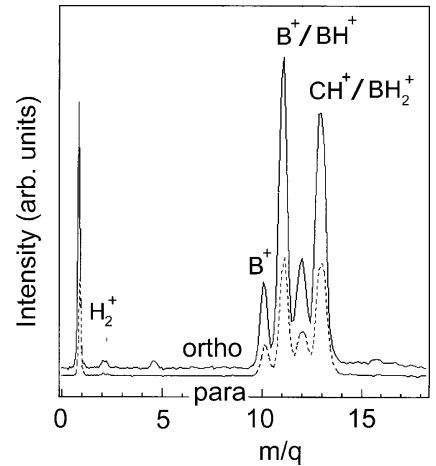

Figure 4. Enhanced time-of-flight (TOF) mass spectra in the region of $m / q=0-18$, adapted from Figure 3. Note that in this display, peak height is not a reliable indicator of peak intensity.

with particularly prominent yields of $\mathrm{Y}_{3}{ }^{+}$and $\mathrm{Y}_{6}{ }^{+}$. Note that because of the 20:80 ${ }^{10} \mathrm{~B}:{ }^{11} \mathrm{~B}$ relative abundance, each ion peak (except for the $\mathrm{Y}_{1}^{+}$signal, shown in detail in Figure 4) is actually a family of peaks which are not resolved in the TOF spectra.

Above the core excitation threshold (in the region of 188.9 $\mathrm{eV}$ for the $\mathrm{B} 1 \mathrm{~s}$ threshold) the very low parent ion yield in the photoionization measurements might be considered to be a consequence of core hole decay leading to extensive ionic fragmentation, including large amounts of multiple ionization, almost all of which ends up as ion pairs. However, the parent ion yield is also very small below $188 \mathrm{eV}$, in the region of valence ionization, where a greater similarity to the electron impact mass spectrum might be expected. In part this can be attributed to use of a photon energy well above the valence double-ionization threshold $(\sim 35 \mathrm{eV})$, whereas the $70 \mathrm{eV}$ electron impact creates primarily singly ionized states (since electron impact cross sections typically are strong only a few times above threshold). In addition, another important fact is that our TOF system has enhanced sensitivity to low-energy electrons which distorts the ion yields in favor of the doubleionization events which produce two electrons, one of which has low kinetic energy. 


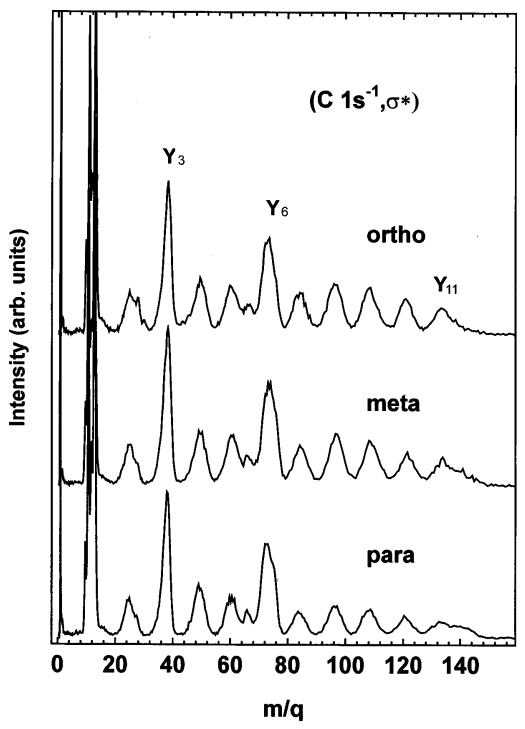

Figure 5. TOF mass spectra of the isomeric carboranes photoionized at the peak in the $290-292 \mathrm{eV}$ region $\left(\mathrm{C} 1 \mathrm{~s} \rightarrow \sigma^{*}\right.$ transition) recorded under the same extraction conditions as used for Figure 3. Spectral data has been processed to remove the underlying $\mathrm{B}$ 1s contribution, which was estimated by adjusting the intensity of the $280 \mathrm{eV}$ TOF spectrum to that of the extrapolated B 1 s continuum intensity at 290$292 \mathrm{eV}$

Figure 5 is the TOF mass spectra of the three carboranes with a photon energy of $290-292 \mathrm{eV}$ on the peak of the $\mathrm{C} 1 \mathrm{~s} \rightarrow \sigma^{*}$ transition which is believed to be the $\mathrm{C}$ 1s counterpart to the $\mathrm{B}$ $1 \mathrm{~s} \rightarrow \sigma^{*}$ transition at $202 \mathrm{eV}$. Since the $\mathrm{C} 1 \mathrm{~s}$ excitation signal is a relatively small proportion of the total photoionization at the $290-292 \mathrm{eV}$ energies used to record the data in Figure 3, the ion yields are largely dominated by the $>70 \%$ contribution from high-energy $\mathrm{B} 1 \mathrm{~s}$ ionization. The underlying $\mathrm{B} 1 \mathrm{~s}$ background signal has been subtracted to get a better picture of the fragmentation processes following $\mathrm{C} 1 \mathrm{~s}$ excitation and ionization.

As with the B 1s excitation, the spectra of the three isomeric species are quite similar to each other, with the greatest difference being a significantly greater contribution from $\mathrm{Y}_{11}{ }^{+}$ species in the metacarborane- and orthocarborane-derived species. There is a very sharp $\mathrm{H}^{+}$production at the $\mathrm{C}$ 1s edge, which is not as strong in the $\mathrm{B}$ 1s edge. Overall the $\mathrm{C} 1 \mathrm{~s}$ and B 1s spectra are quite similar, with the most notable difference being a relatively more prominent contribution from the $\mathrm{Y}_{3}^{+}$ and $\mathrm{Y}_{6}{ }^{+}$species in the $\mathrm{C} 1 \mathrm{~s}$ than the $\mathrm{B} 1 \mathrm{~s}$ region as well as a much larger yield of the lightest fragments, $\mathrm{H}^{+},{ }^{10} \mathrm{BH}^{+} /{ }^{11} \mathrm{~B}^{+}$ $(m / q=11)$, and $\mathrm{CH}^{+} /{ }^{10} \mathrm{BH}_{3}{ }^{+} /{ }^{11} \mathrm{BH}_{2}{ }^{+}(m / q=13)$. These latter signals for the orthocarborane species are off scale in Figure 5.

The sharp edge of closo-carboranes seen in the B 1s region, as shown in Figure 1, are also seen in the ion fragment yields illustrated Figure 6 . The following parent and fragment species were identified in the mass spectrum: $\mathrm{H}^{+},{ }^{10} \mathrm{~B}^{+},{ }^{10} \mathrm{BH}^{+} / 1{ }^{11} \mathrm{~B}^{+}$ $(m / q=11),{ }^{11} \mathrm{BH}^{+}$, and $\mathrm{CH}^{+} /{ }^{10} \mathrm{BH}_{3}{ }^{+} / 11 \mathrm{BH}_{2}{ }^{+}(m / q=13)$, etc. Among the smaller mass fragments, the ${ }^{10} \mathrm{BH}^{+} /{ }^{11} \mathrm{~B}^{+}(m / q=$ 11) and $\mathrm{CH}^{+} / 10 \mathrm{BH}_{3}{ }^{+} /{ }^{11} \mathrm{BH}_{2}{ }^{+}(m / q=13)$ species exhibited higher intensities, as $\operatorname{did} \mathrm{H}^{+}(m / q=1) .{ }^{11} \mathrm{BH}^{+}(m / q=12)$ was among the smaller intensity fragments, as indicated in Figure 4. There are also possible $\mathrm{H}_{2}{ }^{+}$fragments in the ion yield from the carborane samples, as seen in Figure 4, but the $\mathrm{H}_{2}{ }^{+}$fragment yields (if any) at the higher photon energies are quite low. From the ion yield, we know $\mathrm{CH}^{+} /{ }^{10} \mathrm{BH}_{3}{ }^{+} /{ }^{11} \mathrm{BH}_{2}{ }^{+}(\mathrm{m} / q=13)$ loss is facile, as compared to $\mathrm{BH}^{+}$loss, as seen in Figures 3-5. Even

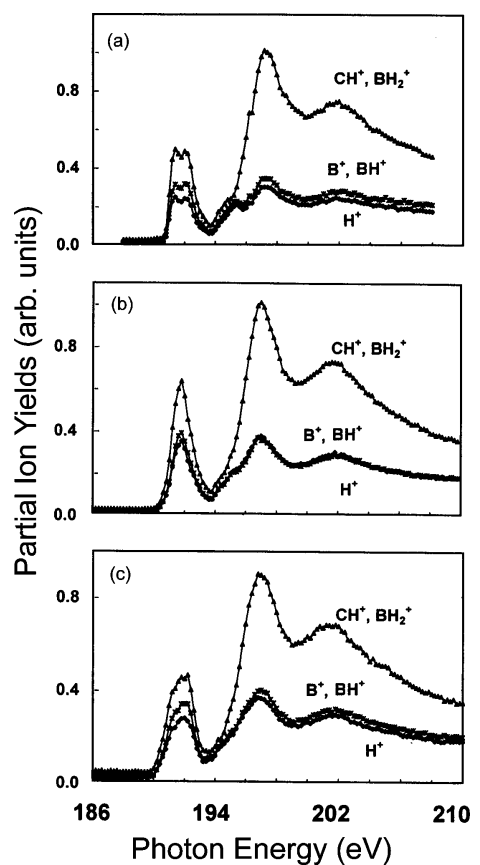

Figure 6. Ion yield data for the major ion fragments of closo-1,2orthocarborane (a), closo-1,7-metacarborane (b), and closo-1,12-paracarborane (c) derived from sequences of TOF mass spectra recorded in the B 1s region using the same conditions as used for Figure 3.

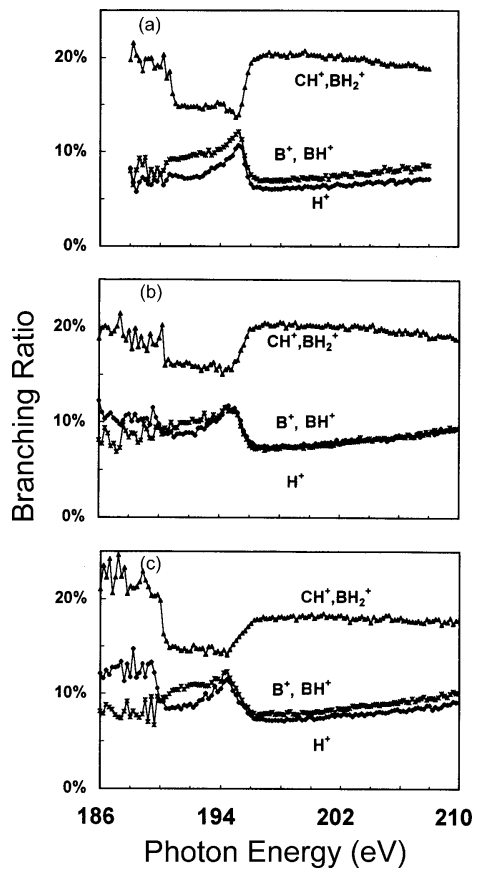

Figure 7. Branching ratio for the major ion fragments of for closo1,2-orthocarborane (a), closo-1,7-metacarborane (b), and closo-1,12paracarborane (c) derived from sequences of TOF mass spectra recorded in the B 1s region using the same conditions as used for Figure 3.

among the electron impact data, among the small ion fragments, $\mathrm{CH}^{+} /{ }^{10} \mathrm{BH}_{3}{ }^{+} /{ }^{11} \mathrm{BH}_{2}{ }^{+}(m / q=13)$ is more abundant than the $\mathrm{BH}^{+}$ fragment. $^{20}$

The partial ion yields and branching ratios for the lighter (and more significant) ion fragments in the B 1s region for the three isomeric species are plotted in Figures 6 and 7, respectively. Again, para-, meta- and orthocarboranes spectra are quite similar, with the main variations being changes in the detailed line shape and partial overlap of $\mathrm{BH}^{+}$and $\mathrm{H}^{+}$branching ratios and partial ion yields for metacarborane. When the signals from the ions $\mathrm{CH}^{+} /{ }^{10} \mathrm{BH}_{3}{ }^{+} /{ }^{11} \mathrm{BH}_{2}{ }^{+}(m / q=13), \mathrm{H}^{+}$and ${ }^{11} \mathrm{~B}^{+} /{ }^{10} \mathrm{BH}^{+}$ 


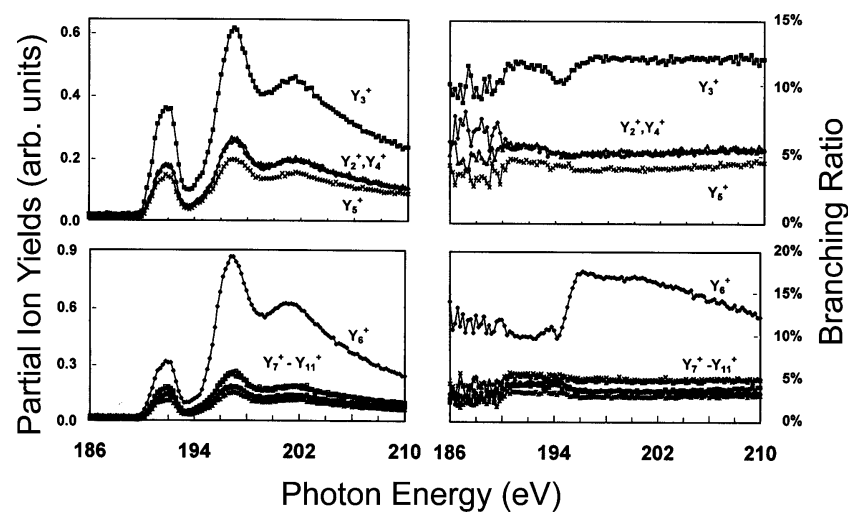

Figure 8. Ion yield and branching ratio data for $\mathrm{Y}_{x}{ }^{+}$ions (where $\mathrm{Y}=$ $\mathrm{BH}$ or $\mathrm{CH}$, as indicated in Figure 3) fragments of closo-1,2orthocarborane derived from sequences of TOF mass spectra recorded in the B 1s region using the same conditions as used for Figure 3.

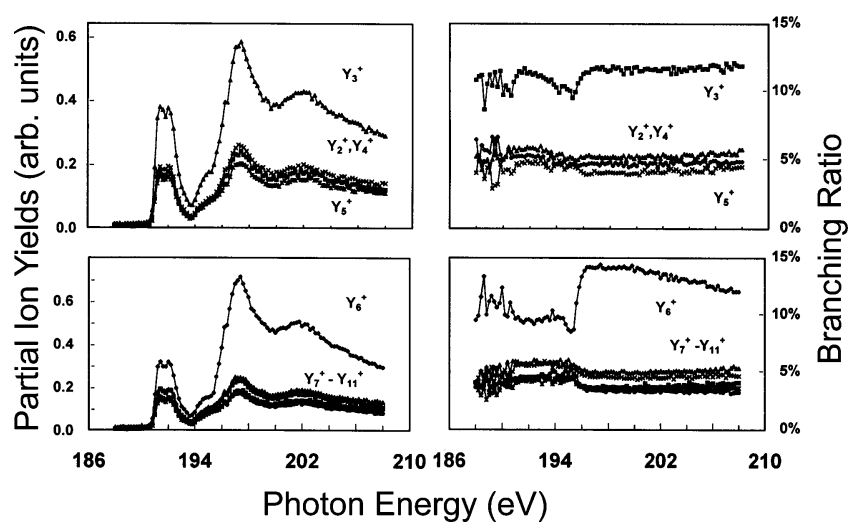

Figure 9. Ion yield and branching ratio data for $\mathrm{Y}_{x}^{+}$ions (where $\mathrm{Y}=$ $\mathrm{BH}$ or $\mathrm{CH}$, as indicated in Figure 3) fragments of closo-1,12paracarborane derived from sequences of TOF mass spectra recorded in the B 1s region using the same conditions as used for Figure 3.

$(m / q=11)$ are compared, the strong signal is associated with $\mathrm{CH}^{+} /{ }^{10} \mathrm{BH}_{3}{ }^{+} /{ }^{11} \mathrm{BH}_{2}{ }^{+}(m / q=13)$ followed by $\mathrm{B}^{+}$and $\mathrm{H}^{+}$. The changes in ion yield are most dramatic at the absorption core threshold below about $192 \mathrm{eV}$ for the B 1s but also increase dramatically at the ionization limits, as determined by XPS ${ }^{17,21}$ and excitations to antibonding $\sigma^{*}$ orbitals of unspecified symmetry, ${ }^{13,17}$ at energies above $194 \mathrm{eV}$, as noted above. The core ionization energy is approximately the core-level binding energy of Figure 2 plus the energy difference between the chemical potential and the vacuum level, the latter being the work function of the condensed phase, i.e., $188.7( \pm 0.2)+5.5$ $( \pm 1) \mathrm{eV}$ or about $194 \mathrm{eV}$.

For the heavier $\mathrm{Y}_{x}+$ ion (where $\mathrm{Y}=\mathrm{BH}$ or $\mathrm{CH}$ ) fragments, the ion yields and branching ratio have been plotted for orthocarborane (Figure 8) and paracarborane (Figure 9). $\mathrm{Y}_{3}$ and $\mathrm{Y}_{6}$ are the most prominent in both cases, although the branching ratios differ somewhat from one isomer to the next. These heavy ion yields also change dramatically at excitations to antibonding $\sigma^{*}$ orbitals of unspecified symmetry above $194 \mathrm{eV} \cdot{ }^{13,17}$ Regrettably, a direct relationship between the excitation to specific unoccupied orbitals and the ion fragment yield cannot be determined from this data.

In spite of differences in the heavy $\mathrm{Y}_{x}{ }^{+}$ion (where $\mathrm{Y}=\mathrm{BH}$ or $\mathrm{CH}$ ) fragment yields, overall there is little difference among the partial yields of the isomeric species and relatively little change in individual ion or ion pair yields, which are a result of fission of the doubly or multiply charged molecules, aside from a major step up or step down in specific channels at the onsets of B 1 s core excitation and ionization. ${ }^{13,17}$ These changes at the ionization threshold are qualitatively consistent with changes in the estimated photoionization efficiency. ${ }^{13}$ Thus, any selectivity among these three species which may exist with regard to properties of boron carbide films prepared by X-ray assisted CVD is more likely to be associated with specificity of the chemistry of fragments or due to different relaxation processes (which are not known) rather than selectivity in the initial excitation.

At issue is the origin for the very high production of $\mathrm{CH}^{+} /$ ${ }^{10} \mathrm{BH}_{3}{ }^{+} /{ }^{11} \mathrm{BH}_{2}{ }^{+}(m / q=13)$ fragments in the photofragmentation process. This can be understood, in part, from the energetics associated with photoionization and fragmentation. As seen in Figure 7, however, these yields also increase where excitations to antibonding $\sigma^{*}$ orbitals of unspecified symmetry occur ${ }^{13,17}$ at energies above $194 \mathrm{eV}$. The application of energetics to the heavy $\mathrm{Y}_{x}{ }^{+}$ion (where $\mathrm{Y}=\mathrm{BH}$ or $\mathrm{CH}$ ) fragment yields (Figures 8 and 9) is more difficult as specific fragment ion identification is fraught with difficulties based on the data presented here, but again these yields also increase where excitations to antibonding $\sigma^{*}$ orbitals of unspecified symmetry occur at energies above $194 \mathrm{eV}$.

Single photoion creation is relatively more straightforward to model but is generally best applicable near the appearance and ionization potentials. Beginning at the near edge regime, there are numerous complications to be considered, including matrix element effects associated with excitations to antibonding $\sigma^{*}$ orbitals. Of course, as noted in the Introduction, multiple ion fragmentation is not only possible but likely above the B 1s threshold. Such multiple photoion creation would involve a molecular fission process with complex thermodynamic considerations. These complications will be addressed in a subsequent paper.

\section{Energetics of closo-Carborane Decomposition}

The measured yields depend on the ionization process and associated fragmentation (Figure 3), e.g., electron impact versus photoionization. The dominant signal is loss of one $\mathrm{H}$ atom for the electron impact mass spectrum, while for photoionization mass spectra, the majority of the TOF signal are associated with $(\mathrm{B} / \mathrm{BH})_{x}{ }^{+}, \mathrm{CH}^{+} /{ }^{10} \mathrm{BH}_{3}{ }^{+} /{ }^{11} \mathrm{BH}_{2}{ }^{+}(m / q=13)$, or $(\mathrm{CH})_{x}{ }^{+}$ions. In order to understand the difference yields in the core-level resonant photoionization processes and evaluate the thermal stability of the closo-carboranes, the energetics for several reactions which involve loss of small fragment ions of carbon, boron, and hydrogen atoms have been calculated for all three parent closo-carboranes using both the PM3 semiempirical model and DFT, as shown in Figures 10-12. There are many (energetically) different site symmetry combinations of boron, hydrogen, and carbon atoms that are candidates for ion (and neutral) fragmentation. This is especially true for the meta- and orthocarboranes because of their lower symmetry structures $\left(C_{2 v}\right.$ instead of $D_{5 d}$ ).

The symmetrically distinct possibilities for closo-carboranes are associated with different energies, as illustrated in Figures 10-12, where the fragmentation energies are plotted in ascending order, as ascertained using DFT. Also shown for comparison are values obtained using the semiempirical PM3 approach, which differ significantly in absolute energies but typically show the same trends as DFT, as seen in Figures 10-12. As expected, the fragmentation energies of the three isomeric species are quite similar, consistent with the photoionization and fragmentation experimental results. For orthocarboranes, the minimum energies to remove atoms are typically near the site of carbon atoms except for the loss of $\mathrm{H}^{+}$from orthocarborane. In the case of 

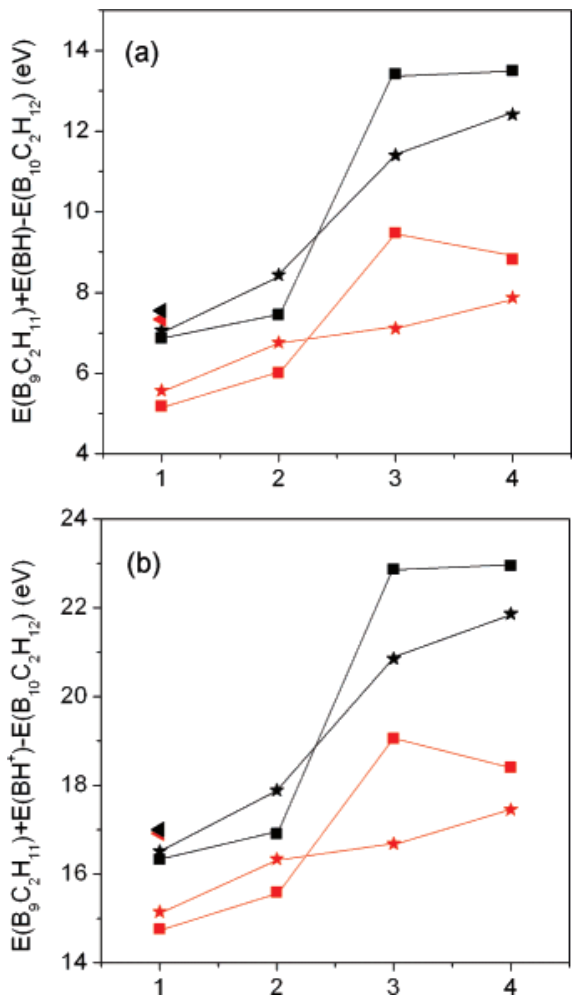

Figure 10. Calculated ion fragmentation energies for $\mathrm{BH}$ (a) and $\mathrm{BH}^{+}$ (b) from closo-1,2-orthocarborane (stars), closo-1,7-metacarborane (squares), and closo-1,12-paracarborane (triangles) using the PM3 semiempirical method (red) and density functional theory (DFT) (black). $1,2,3$, and 4 represent boron hydrogen bonds removed from site ( 2 or $3),(5$ or 12$),(9$ or 10$)$, and $(4,6,8$, or 11) for closo-1,7-metacarborane accordingly and $(3$ or 6$),(9$ or 12$),(8$ or 10$)$, or $(4,5,7,11)$ for closo1,2-orthocarborane accordingly using the numbering scheme in Figure 1.

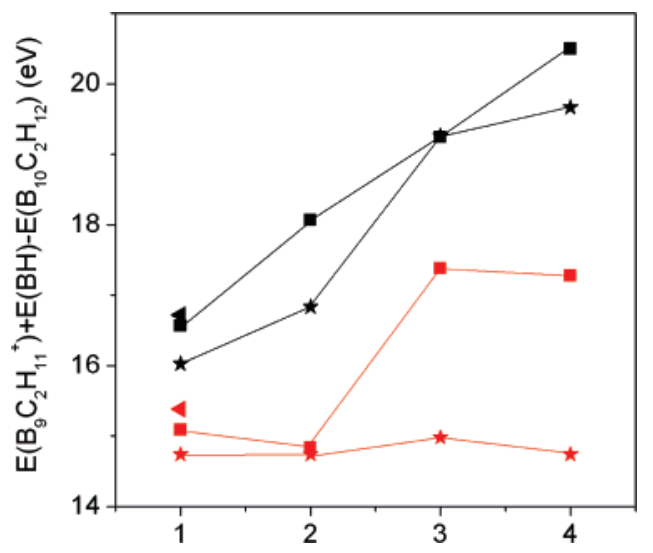

Figure 11. Calculated ion fragmentation energies for $\mathrm{B}_{9} \mathrm{C}_{2} \mathrm{H}_{11}{ }^{+}$from closo-1,2-orthocarborane (stars), closo-1,7-metacarborane (squares), and closo-1,12-paracarborane (triangles) using the PM3 semiempirical method (red) and density functional theory (DFT) (black). 1, 2, 3, and 4 represent carbon hydrogen bonds removed from site (5 or 12), ( 2 or $3)$, (9 or 10), and $(4,6,8$, or 11) for closo-1,7-metacarborane accordingly and (3 or 6$),(9$ or 12$),(8$ or 10$)$, or $(4,5,7$, or 11$)$ for closo-1,2-orthocarborane accordingly using the numbering scheme in Figure 1.

meta- and paracarboranes, loss of $\mathrm{H}^{+}$from sites near the carbon are favored. In the production of $\mathrm{H}_{2}$, it has already been noted that the initial state site does play a role with pairwise (adjacent sites) $\mathrm{H}$ loss favored, with one site including a carbon atom. ${ }^{12}$ The absence of $\mathrm{H}_{2}{ }^{+}$in the data can be understood as formation of this ion fragment is very energy expensive, requiring 28.5 $\mathrm{eV}$ or more per molecule $(2750 \mathrm{~kJ} / \mathrm{mol})$.

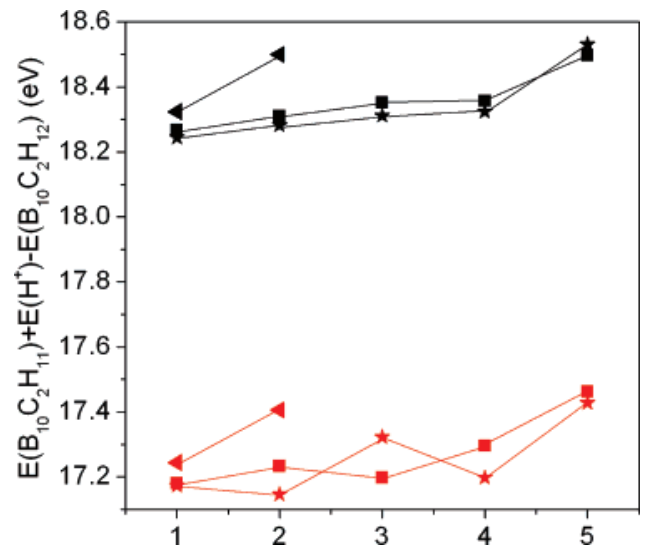

Figure 12. Calculated ion fragmentation energies for $\mathrm{H}^{+}$from closo1,2-orthocarborane (stars), closo-1,7-metacarborane (squares), and closo1,12-paracarborane (triangles) computed using the PM3 semiempirical method (red) and density functional theory (DFT) (black). 1, 2, 3, 4, and 5 represent hydrogens removed from site (9 or 10), $(4,6,8$ or 11), (5 or 12$),(2$ or 3$)$, and (1 or 7) for closo-1,7-metacarborane accordingly and (8 or 10), (9 or 12), (3 or 6$),(4,5,7$, or 11), or (1 or 2$)$ for closo1,2-orthocarborane accordingly using the numbering scheme in Figure 1. For closo-1,12-paracarborane, 1 represents hydrogen removed from the boron atom sites, while 2 represents carbon atom sites.

On the basis of the DFT, the energetics of closo-carboranes fragmentation and fragment ionization have been used to construct thermodynamic cycles to illustrate the reaction energies, as shown in Figure 13. Each value is the minimum energy calculation among all possible symmetrically inequivalent possibilities. The choice of thermodynamic cycles is based on the observed ion fragmentations, removing $\mathrm{CH}, \mathrm{CH}^{+}, \mathrm{BH}, \mathrm{BH}^{+}$, $\mathrm{BH}_{2}, \mathrm{BH}_{2}{ }^{+}, \mathrm{H}_{2}, \mathrm{H}, \mathrm{H}^{+}, \mathrm{BCH}_{3}$, and $\mathrm{BCH}_{3}{ }^{+}$from each of the three isomers of the closo-carboranes, as undertaken by us for far more simple parent molecular species like $\mathrm{CX}_{4}(\mathrm{X}=\mathrm{F}, \mathrm{Cl}$, $\mathrm{Br}, \mathrm{I}),^{22}$ the substituted metallocenes, ${ }^{23}$ and others. ${ }^{24}$

The calculated energetics are consistent with formation of ${ }^{11} \mathrm{BH}_{2}{ }^{+}$over $\mathrm{CH}^{+}$or ${ }^{11} \mathrm{BH}^{+}$. While we cannot distinguish $\mathrm{CH}^{+}$/ ${ }^{10} \mathrm{BH}_{3}{ }^{+} /{ }^{11} \mathrm{BH}_{2}{ }^{+}$, the most probable formation paths of $\mathrm{BH}_{2}{ }^{+}$ fragment ions are

$$
\mathrm{B}_{10} \mathrm{C}_{2} \mathrm{H}_{12} \rightarrow \mathrm{B}_{9} \mathrm{C}_{2} \mathrm{H}_{10}+\mathrm{BH}_{2}^{+}+\mathrm{e}
$$

at an energy cost of about $0.5 \mathrm{eV}$ per molecule (approximately $48 \mathrm{~kJ} / \mathrm{mol}$ ) less than is the case for the most probable formation paths of $\mathrm{BH}^{+}$fragment ions, which are

$$
\mathrm{B}_{10} \mathrm{C}_{2} \mathrm{H}_{12} \rightarrow \mathrm{B}_{9} \mathrm{C}_{2} \mathrm{H}_{11}+\mathrm{BH}^{+}+\mathrm{e}
$$

and at an energy cost of about $2.5-3.5 \mathrm{eV}$ per molecule (240$338 \mathrm{~kJ} / \mathrm{mol}$ ) less again than is the case for the most probable formation paths of $\mathrm{CH}^{+}$fragment ions, which are

$$
\mathrm{B}_{10} \mathrm{C}_{2} \mathrm{H}_{12} \rightarrow \mathrm{B}_{9} \mathrm{C}_{2} \mathrm{H}_{11}+\mathrm{CH}^{+}+\mathrm{e}
$$

as $\Delta H_{\mathrm{p}}$ (paracarborane), $\Delta H_{\mathrm{m}}$ (metacarborane), and $\Delta H_{\mathrm{o}}$ (orthocarborane) where for the foremost reaction, the energies are $16.52,15.46$, and $15.62 \mathrm{eV}$, respectively $(1594,1492$, and 1507 $\mathrm{kJ} / \mathrm{mol}$, respectively). On the basis of these values and those summarized in Figure 13, the favored fragmentations, based on energetic considerations alone, are $\mathrm{BH}_{2}{ }^{+}$(by about $0.5-0.9 \mathrm{eV}$ per molecule or $48-87 \mathrm{~kJ} / \mathrm{mol}$ ) $>\mathrm{BH}^{+}$(by about $1-2 \mathrm{eV}$ per molecule or $96-193 \mathrm{~kJ} / \mathrm{mol}$ ) $>\mathrm{H}^{+}$(by about $1.6-2.3 \mathrm{eV}$ per molecule or $154-222 \mathrm{~kJ} / \mathrm{mol}$ ) $>\mathrm{CH}^{+}$for all the closocarboranes. 


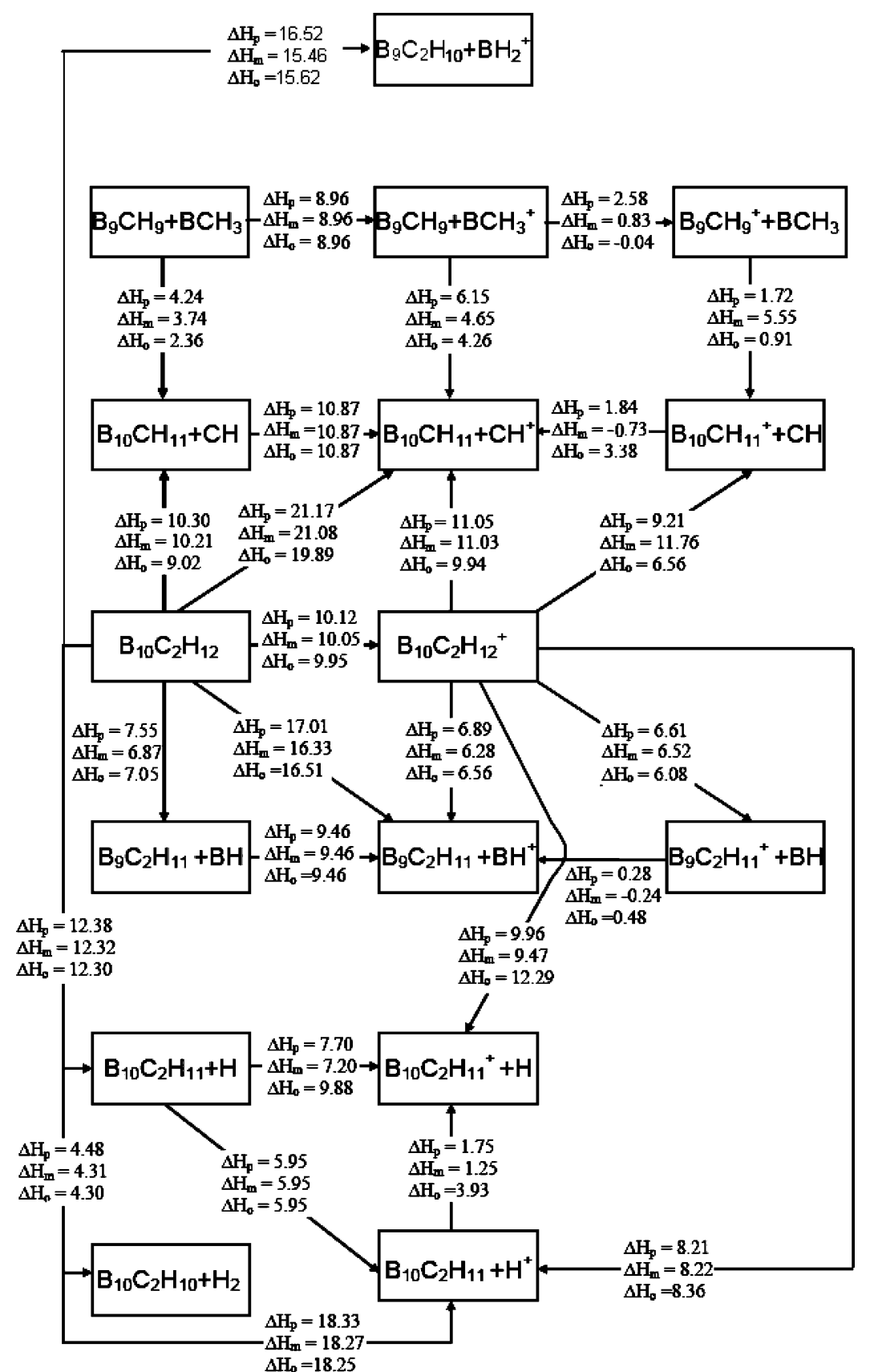

Figure 13. Energetics of closo-1,2-orthocarborane $\left(E_{\mathrm{o}}\right)$, closo-1,7-metacarborane $\left(E_{\mathrm{m}}\right)$, and closo-1,12-paracarborane $\left(E_{\mathrm{p}}\right)$ neutral and ionic fragmentation. All energies were calculated using density functional theory and are given in units of eV/molecule.

The thermodynamic cycles indicate the most likely ion species are $\mathrm{BH}_{2}{ }^{+}$and $\mathrm{B}_{9} \mathrm{C}_{2} \mathrm{H}_{11}{ }^{+}$. The latter may be consistent with decomposition initiated by core to bound photoexcitations, illustrated in Figures 3-4 and 6-9, but we are limited by the fact that we cannot distinguish $\mathrm{BH}_{2}{ }^{+}$and $\mathrm{CH}^{+}$in our data. Given the large size of some of the ion fragments, kinetic barriers to the fragment ion formation may be a significant hindrance, as could be symmetry, ${ }^{22}$ and this has not been considered in the calculations undertaken here. More importantly, above the core threshold, molecular fission and multiple ion fragment production is likely. ${ }^{25}$ A similar problem is evident in that $\mathrm{H}^{+}$ production is more intense than $\mathrm{BH}^{+}$well below the $\mathrm{B}$ 1s core threshold (as determined by XPS in Figure 2) inconsistent with the energetics of ion fragmentation, which slightly favors $\mathrm{BH}^{+}$ production over $\mathrm{H}^{+}$, as observed in the region of the $\mathrm{B} 1 \mathrm{~s}$ threshold and above.
Excited-state lifetimes or excitations to specific unoccupied molecular orbitals may play a significant role in the ion fragmentation yields, as suggested by the strong photon energy dependence of the ion fragmentation yields (Figures 6-9). Kinetic barriers to fragmentation are certainly not considered in these energetic calculations.

\section{Conclusion}

Although we cannot distinguish between $\mathrm{CH}^{+} /{ }^{10} \mathrm{BH}_{3}{ }^{+} / 11 \mathrm{BH}_{2}{ }^{+}$ in the TOF mass spectroscopy of the photofragmentation in the region of the $\mathrm{B} 1 \mathrm{~s}$ and $\mathrm{C} 1 \mathrm{~s}$ core thresholds, the energetics of decomposition favors formation of $\mathrm{BH}_{2}{ }^{+}$rather than the mass equivalent $\mathrm{CH}^{+}$. The possible long-lived bound core excitations result in the high $\mathrm{H}^{+}$and $\mathrm{B}^{+}$production, but the strong variations in fragment ion yields with photon energy implicate kinetic and symmetry barriers to some ion fragment formation. In addition, 
a direct relationship between excitation to specific unoccupied orbitals and ion fragment yield cannot be determined from this data and is not evident from the present results. As a result, energetics alone is not a reliable guide to fragmentation yields, particularly above the B 1s core threshold where multiple fragment creation from the photofragmentation is likely. It is believed there is significant bias toward low-energy electrons, and thus, events in which stepwise electronic decay occur, giving rise to both copious fragmentation and slow electrons.

As plasma-enhanced CVD is the method of choice for fabricating semiconducting boron carbides, the chemistry of the CVD process is necessarily complex. Photoionization at X-ray energies in the region of $\mathrm{B} 1 \mathrm{~s}$ and $\mathrm{C} 1 \mathrm{~s}$ edges is very effective at inducing molecular fragmentation, and thus, a study of ion yields at these photon energies may give some insight into the fragmentation mechanisms. Since both plasma-enhanced chemical vapor deposition and white light synchrotron-initiated decomposition are methods used to deposit semiconducting boron carbides, both ion and neutral fragmentation pathways may be involved in the CVD process, but extra molecular interactions may also occur in such processes as part of the deposition processes. Here we attempted to characterize ionic fragmentation of the singly charged closo-carboranes. Double and multiple ion fragmentation almost certainly does occur in the core-level regime and must be explored as well.

Acknowledgment. This work was financially supported by the Natural Sciences and Engineering Research Council of Canada, the National Science Foundation, through grants CHE0415421, CHE-0650453, and ECS 0725881. We thank J. T. Spencer, N. M. Boag, J. Choi, and the staff of the Advanced Light Source (funded by DoE) for their assistance.

\section{References and Notes}

(1) ) Caruso, A. N.; Billa, R. B.; Balaz, S.; Brand, J. I.; Dowben, P. A. J. Phys.: Condens. Matter 2004, 16, L139-L146.

(2) ) Robertson, B. W.; Adenwalla, S.; Harken, A.; Welsch, P.; Brand, J. I.; Dowben, P. A.; Claassen, J. P. Appl. Phys. Lett. 2002, 80, 36443646.

(3) ) Robertson, B. W.; Adenwalla, S.; Harken, A.; Welsch, P.; Brand, J. I.; Claassen, J. P.; Boag, N. M.; Dowben, P. A. Advances in Neutron Scattering Instrumentation (Anderson, I. S., Guérard, B., Eds.). Proc. SPIE 2002, 4785, 226-233.

(4) ) Adenwalla, S.; Billa, R.; Brand, J. I.; Day, E.; Diaz, M. J.; Harken, A.; McMullen-Gunn, A. S.; Padmanabhan, R.; Robertson, B. W. Penetrating Radiation Systems and Applications V. Proc. SPIE 2003, 5199, 70-74.

(5) ) Osberg, K.; Schemm, N.; Balkir, S.; Brand, J. I.; Hallbeck, S.; Dowben, P. A.; Hoffman, M. W. IEEE Sens. J. 2006, 6, 1531-1538.

(6) ) Caruso, A. N.; Dowben, P. A.; Balkir, S.; Schemm, N.; Osberg, K.; Fairchild, R. W.; Barrios Flores, O.; Balaz, S.; Harken, A. D.; Robertson, B. W.; Brand, J. I. Mater. Sci. Eng. B 2006, 135, 129-133.

(7) ) Day, E.; Diaz, M. J.; Adenwalla, S. J. Phys. D: Appl. Phys. 2006, $39,2920-2924$.
(8) ) Balaz, S.; Dimov, D. I.; Boag, N. M.; Nelson, K.; Montag, B.; Brand, J. I.; Dowben, P. A. Appl. Phys. A 2006, 84, 149-159.

(9) ) Lunca-Popa, P.; Brand, J. I.; Balaz, S.; Rosa, L. G.; Boag, N. M.; Bai, M.; Robertson, B. W.; Dowben, P. A. J. Phys. D.: Appl. Phys. 2005, 38, 1248-1252.

(10) ) Balaz, S.; Caruso, A. N.; Platt, N. P.; Dimov, D. I.; Boag, N. M.; Brand, J. I.; Losovyj, Ya. B.; Dowben, P. A. J. Phys. Chem. B 2007, 111, 7009-7016.

(11) ) Caruso, A. N.; Balaz, S.; Xu, B.; Dowben, P. A.; McMullenGunn, A. S.; Brand, J. I.; Losovyj, Y. B.; Mcllroy, D. N. Appl. Phys. Lett. 2004, 84, 1302-1304.

(12) ) Park, K.; Pederson, M. R.; Boyer, L. L.; Mei, W. N.; Sabirianov, R. F.; Zeng, X. C.; Bulusu, S.; Curran, S.; Dewald, J.; Day, E.; Adenwalla, S.; Diaz, M. J.; Rosa, L. G.; Balaz, S.; Dowben, P. A. Phys. Rev. B 2006 73, 035109.

(13) ) Hitchcock, A. P.; Urquhart, S. G.; Wen, A. T.; Kilcoyne, A. L. D.; Tyliszczak, T.; Rühl, E.; Kosugi, N.; Bozek, J. D.; Spencer, J. T.; McIlroy, D. N.; Dowben, P. A. J. Phys. Chem. B 1997, 101, 3483.

(14) ) (a) Hitchcock, A. P.; Neville, J. J. In Chemical Applications of Synchrotron Radiation; Sham, T. K., Ed.; Advanced Series in Physical Chemistry; World Scientific: Singapore, 2002; Vol. 12A, pp 154-227. (b) Langer, B.; Berrah, N.; Farhat, A.; Hemmers, O.; Bozek, J. D. Phys. Rev. A 1996, 53, R1946.

(15) ) Wiley, C. W.; McLaren, I. H. Rev. Sci Instrum. 1955, 26, 1150.

(16) ) Yakovkin, I. N.; Dowben, P. A. Surf. Rev. Lett. 2007, 14, 481487.

(17) ) Hitchcock, A. P.; Wen, A. T.; Lee, S.; Glass, Jr., J. A.; Spencer, J. T.; Dowben, P. A. J. Phys. Chem. 1993, 97, 8171.

(18) ) Lee, S. W.; Mazurowski, J.; O’Brien, W. L.; Dong, Q. Y.; Jia, J. J.; Callcott, T. A.; Tan, Y. X.; Miyano, K. E.; Ederer, D. L.; Mueller, R. D.; Dowben, P. A. J. Appl. Phys. 1993, 74, 6919. Jiménez, I.; Sutherland, D. G. J.; van Buuren, T.; Carlisle, J. A.; Terminello, L. J.; Himpsel, F. J. Phys. Rev. B 1998, 57, 13167.

(19) ) Vasyukova, N. I.; Nekrasov, Y. S.; Sukharev, Y. N.; Mazunov, V. A.; Sergeev, Y. L.; Akad, I. Z. V. Nauk SSSR Ser. Khim. 1984, 6, 1337 (transl.: 1223).

(20) ) Ardini, L. C.; Fehlner, T. P. Int. J. Mass. Spec. Ion Phys. 1972, 10, 489; NIST Mass Spectrometry Data Center Collection, 2006 copyright by the U.S. Secretary of Commerce on behalf of the United States of America, http://webbook.nist.gov/cgi/cbook.cgi?ID=C16986246\&Units= SI\&Mask=200\#Mass-Spec.

(21) ) Allison, D. C.; Johansson, G.; Allan, C. J.; Gelius, U.; Siegbahn, H.; Allison, J.; Siegbahn, K. J. Electron Spectrosc. Relat. Phenom. 1972 $1,269$.

(22) ) Kime, Y. J.; Driscoll, D. C.; Dowben, P. A. J. Chem. Soc. Faraday Trans. II 1987, 83, 403. Driscoll, D. C.; Bishop, J. A.; Sturm, B. J.; Dowben, P. A.; Olsen, C. G. J. Vac. Sci. Technol. 1986, A4, 823.

(23) ) Barfuss, S.; Grade, M.; Hirschwald, W.; Rosinger, W.; Boag, N. M.; Driscoll, D. C.; Dowben, P. A. J. Vac. Sci. Technol. 1987, A5, 1451. Stauf, G.; Driscoll, D. C.; Dowben, P. A.; Barfuss, S.; Grade, M. Thin Solid Films 1987, 153, 421-430. Barfuss, S.; Emrich, K.-H.; Hirschwald, W.; Dowben, P. A.; Boag, N. M. J. Organomet. Chem. 1990, 391, 204-218.

(24) ) Grade, M.; Rosinger, W.; Dowben, P. A. Ber. Bunsen-ges. Phys Chem. 1984, 88, 65-71. Stauf, G. T.; LaGraffe, D.; Dowben, P. A.; Emrich, K.; Barfuss, S.; Hirschwald, W.; Boag, N. M. Z. Naturforsch. A 1988, 43, 758-764. Stauf, G. T.; Dowben, P. A.; Emrich, K.; Barfuss, S.; Hirschwald, W.; Boag, N. M. J. Phys. Chem. 1989, 93, 749-753. Emrich, K.-H.; Stauf, G. T.; Hirschwald, W.; Barfuss, S.; Dowben, P. A.; Birge, R. R.; Boag, N. M. Materials Research Society Symposium Proceedings; Gross, M., Jasinski, J. M., Yates, J., Eds.; Materials Research Society: Warrendale, PA, 1989, Vol. 131, pp 401-406.

(25) ) Manuscript in preparation. 